Revista Perspectiva Online: Humanas \& Sociais Aplicadas Julho de 2017, Vol.7, n 19 , p.54-64

ISSN: 2236-8876 (Online)

DOI:10.25242/887671920171178

\title{
POR UM SORRISO SEM DROGAS: A REALIDADE DA REDE DE APOIO EM CAMPOS DOS GOYTACAZES
}

\author{
Érica Henrique Ribeiro-Andrade ${ }^{1} *$, Maria Francisca Teresa Barbosa Barreto ${ }^{2}$ \& Vitória \\ Santana Chagas ${ }^{2}$
}

\begin{abstract}
RESUMO
RIBEIRO-ANDRADE, E.H.; BARRETO, M. F. T. B.; CHAGAS, V.S. Por Um Sorriso Sem Drogas: A Realidade Da Rede De Apoio Em Campos Dos Goytacazes. Perpectivas Online: Humanas \& Sociais Aplicadas, v.7, n.19, p. 5464, 2017.

A cidade de Campos dos Goytacazes/RJ,conta com poucos estudos desenvolvidos sobre a realidade do sujeito drogadicto. $\mathrm{O}$ presente projeto objetiva levar informações ao sujeito drogadicto e/ou aos seus familiares, bem como sensibilizar os mesmos quanto à possibilidade de intervenção sob a drogadição por meio da reflexão e assimilação de ajuda local. O projeto envolve as características de pesquisa descritiva, estudo de campo, culminando numa ação social. Nesta primeira etapa utilizar-se-á pesquisa documental e observação in loco na obtenção dos dados sobre a rede de apoio ao sujeito drogadicto existente em Campos. Os resultados apresentados

diversificada quanto a sua tipologia, sendo as instituições religiosas de grande expressão. Identificou-se a existência de um CAPS-AD, treze grupos de AA e um Escritório Central de AA, sete grupos de NA, sete comunidades terapêuticas, dois Hospitais Psiquiátricos, uma Emergência Psiquiátrica e três grupos de Pastoral da Sobriedade. Conclui-se que com os dados já identificados é possível iniciar a editoração do livreto que será distribuído publicamente, todavia, entende-se que o levantamento de informações que inicialmente imaginou-se ser apenas uma primeira etapa, deverá ser mantido até o final do projeto.
\end{abstract} preliminarmente dizem respeito à primeira etapa do projeto. A rede de apoio localizada mostrou-se

Palavras-chave: Drogadição, Informação, Sensibilização, Psicologia. 


\begin{abstract}
The city of Campos dos Goytacazes/RJ owns a few studies developed about drug addict's reality. The present project aims to informations to drug addict and/or to your relatives, such as to sensitize them face with the possibility of intervention in drug addiction through reflection and assimilation of local help. The Project involves characteristics of descriptive research, field study, result a social action. In this first stage will be used a documentary research and observation in loco in acquisition data about the support network for the drug addict in Campos. The results presented initially correspond to the first stage of the

diversified concerning your typology, being the religious institutions of great expression. Was identified the existence of a CAPS-AD, thirteen groups of AA and one Central Office of AA, seven groups of NA, seven therapies communities, two Psychiatric Hospitals, one Psychiatric Emergency and three groups of Pastoral of Sobriety. It is concluded that with data already identified it's possible to start publishing the booklet o be distributed publicly, however, it is understood that the survey information than originally it was assumed to be the first stage, should be maintained until the end of the Project.
\end{abstract} Project. The support network localized showed

Keywords: Drug addiction; Information; Sensitization; Psychology.

\footnotetext{
${ }^{1}$ Institutos Superiores de Ensino do CENSA - ISECENSA - Laboratório de Estudos sobre a Drogadição- Rua Salvador Correa, 139, Centro, Campos dos Goytacazes, RJ, CEP: 28035-310, Brasil;

${ }^{2}$ Acadêmicas de Psicologia ISECENSA- Institutos Superiores de Ensino do CENSA - ISECENSA - Rua Salvador Correa, 139, Centro, Campos dos Goytacazes, RJ, CEP: 28035-310, Brasil;

$\left.{ }^{*}\right)$ e-mail: ericahribeiro@yahoo.com.br

Data de chegada: 19/04/2017 Aceito para publicação: 09/06/2017
} 


\section{INTRODUÇÃO}

A cidade de Campos dos Goytacazes/RJ tem mais de 400 mil habitantes, e pode ser vista como um centro Universitário na Região Norte Fluminense, uma vez sediar várias instituições de ensino superior tanto público como privado. Ainda assim, existem poucos estudos desenvolvidos sobre a realidade do sujeito drogadicto tendo a cidade de Campos dos Goytacazes como variável de pesquisa. Trabalhos como os de Ribeiro-Andrade (2013a), Ribeiro-Andrade (2013b) e Pinheiro, Rangel e Lima (2011), podem ser mencionados como alguns destes.

Estes últimos autores, por exemplo, se preocuparam em estudar a problemática ligada aos adolescentes que consomem substâncias químicas e são estudantes do ensino médio de escolas públicas de Campos dos Goytacazes/RJ. Os autores buscaram atingir essa problemática na maior cidade do interior fluminense de modo que realizassem entrevistas junto às organizações que trabalham com a prevenção de uso de drogas, e uma pesquisa educacional com este tema fora implementada. Como principal resultado, a equipe propôs uma ação educativa nas escolas da região.

Os outros dois trabalhos mencionados apresentam diferentes aspectos sobre a drogadição feminina tendo como foco de pesquisa mulheres internas em instituições na cidade supracitada. No entanto, ainda existe uma grande necessidade de mapeamento da situação que a cidade vive em relação ao problema de drogadição, demandando que mais estudos e intervenções sejam realizados.

É nesta direção que o presente projeto se dirige, com vistas a levar informações ao sujeito drogadicto e/ou aos seus familiares, bem como pretendendo sensibilizar os mesmos quanto à possibilidade de intervenção sob este estado por meio da reflexão e assimilação de ajuda local. O presente relatório apresenta os resultados iniciais da concretização deste projeto.

\section{METODOLOGIA}

Conforme Gil (2010), o projeto tem características de uma pesquisa descritiva, um estudo de campo e uma ação social.

Trata-se de uma pesquisa descritiva por ter como foco de trabalho a descrição das características de um determinado fenômeno, qual seja, o perfil das instituições de apoio ao drogadicto e familiares na cidade de Campos dos Goytacazes/RJ. No referido levantamento de dados a busca é de informações como: história da Instituição, modalidade de adesão à instituição, tipo de subsídios financeiros necessários para recepção do usuário e ou/ familiar, capacidade de acolhimento (número de pessoas que podem ser acolhidas ao mesmo tempo), Instalações (estruturas de alojamento e demais dependências), e modalidade de tratamento (serviços oferecidos para o processo de recuperação). Os resultados deste levantamento serão compilados em forma de um livreto com o nome do projeto: "Por um Sorriso sem Drogas", e será distribuído gratuitamente.

Trata-se de um estudo de campo, uma vez que as informações buscadas não estão disponíveis em um documento específico, mas presentes nas instituições que deverão ser identificadas e acessadas pelos pesquisadores. Seja por meio digital ou presencial, as instituições de apoio serão contatadas e caso seja necessário, visitadas pelos pesquisadores, a fim de que o próprio campo nos revele as informações pertinentes. Após os dados serem colhidos, serão não apenas organizados, mas analisados com vistas a traçar um perfil das demandas ainda existentes na cidade no que diz respeito ao apoio ao sujeito drogadicto.

E por fim, trata-se de uma ação social, uma vez que a culminância deste projeto será a realização de um evento para sensibilização contra o uso abusivo de álcool e outras drogas. O referido evento será realizado em local de circulação pública e será gratuito, prevendo também que não haverá nenhum tipo de ônus para a instituição de pesquisa. O evento de culminância contará com a distribuição dos livretos Por um Sorriso sem Drogas, a distribuição de botons para adesão à referida campanha, distribuição de questionários para identificação de um risco ao uso indevido de drogas, e uma apresentação cultural para sensibilização e intervenção na drogadição.

Persp. online: hum. \& sociais aplicada., Campos dos Goytacazes, 19 (7), 54-64, 2017

seer.perspectivasonline.com.br 


\section{Resultados e Discussão}

Em função da metodologia que foi utilizada na etapa de sensibilização, faz-se necessário uma elucidação dos dispositivos que foram utilizados na mesma, quais sejam: a informação, o questionário ASSIST e a apresentação artístico-cultural.

De acordo com Ribeiro e Minayo (2015), o uso de substâncias químicas vem acontecendo há muitos anos como prática religiosa, medicamentosa ou recreativa. Para os autores, uma maior preocupação com direitos dos usuários e os cuidados aos mesmos pode ser percebido no Brasil a partir dos anos 90. Neste sentido, o presente projeto tem como contexto as reflexões pertinentes a Psicologia e sua forma de favorecer aos cuidados à saúde pública no que diz respeito a esta difícil questão social, lançando mão da pesquisa como meio científico de levantamento de informações, mas também como modalidade de intervenção.

Estudos como os de Sanches et al (2010) tem refletido sobre o papel da informação nos diversos estágios do processo adictivo, e acreditam que ainda que seja possível identificar muitas pesquisas abordando os aspectos de risco ao uso de drogas, ainda contamos, no Brasil, com escassos trabalhos quanto aos fatores de proteção, dentre os quais a informação permanece como um tema controverso.

A pesquisa realizada pelos referidos autores considera o termo "informação" como o conjunto de conhecimentos acerca do tema drogas, envolvendo dados sobre os efeitos, as consequências do uso, abuso e dependência. Segundo o referido estudo, $85 \%$ da população não-usuária entrevistada apontou a informação como motivo relevante à negação da experimentação e consequente uso/abuso de substâncias ilícitas.

Silva e Bencke (2015), em sua matéria sobre a Informação e o abuso de drogas, apresentam o pensamento do Dr. Ângelo Campana, Psiquiatra e Presidente da Associação Brasileira de Estudos sobre Álcool e Drogas. Para Campana, o foco de uma campanha preventiva é informar o jovem, procurando postergar ao máximo, e se for possível impedir, o consumo de drogas.

Como questionário de identificação utilizou-se o Teste de Triagem do Envolvimento com Álcool, Cigarro e outras Substâncias (ASSIST), por tratar-se de um instrumento válido, confiável e apto a ser utilizado em serviços para avaliação do nível de relação que uma pessoa apresenta com substancias químicas, e para averiguar se esta relação é de uso ocasional, abusivo ou de dependência. O objetivo do ASSIST é conscientizar os usuários de substâncias psicoativas dos riscos de drogadição que um determinado padrão de uso pode oferecer, sensibilizando-os desta forma, a busca pela rede de apoio local caso necessário. O questionário é de auto-relato e não precisa ser preenchido na presença do pesquisador. O sujeito poderá levá-lo e preenchê-lo no local e em horário de maior conveniência.

O ASSIST foi desenvolvido pela Organização Mundial de Saúde (OMS), e foi validado em sua Versão Brasileira no ano de 2004 por pesquisadores da UNIFESP e da UFPR (Henrique et al. 2004). É um questionário estruturado composto por oito questões sobre nove classes de substâncias psicoativas (tabaco, álcool, maconha, cocaína, estimulantes, sedativos, inalantes, alucinógenos, e opiáceos). As questões investigam o uso dessas substancias na vida do entrevistado mais especificamente durante os últimos três meses. Cada resposta apresenta um escore, que varia de 0 a 4 , e a soma total pode variar de 0 a 20. Conceitua-se a faixa de escore de 0 a 3 como indicativa de uso ocasional, de 4 a 15 como indicativa de abuso e, superior de 16 pontos como sugestiva de dependência.

A Apresentação Cultural programada com culminância do projeto compreende a participação de um cantor de MPB valor reconhecido, com o objetivo de atrair através da arte, diferentes públicos para que se possa tangenciar a reflexão sobre a drogadição. Sobre a referida apresentação Cultural, por ocasião da culminância da pesquisa, vale ressaltar o que estudos atuais têm afirmado sobre a importância da arte na sensibilização do indivíduo.

Segundo Rubim (2012) o homem é dotado de uma capacidade intelectiva que lhe dá a potencialidade de deixar uma atitude meramente passiva para adotar uma posição critica acerca dos estímulos que recebe. Para isto, segundo a autora, é necessário que o homem tenha contato com as mais diferentes produções de linguagem, dentre as quais a produção artística. As mais diversas formas de Arte, neste sentido, são entendidas pela autora como favorecedoras da arte maior que é viver.

Persp. online: hum. \& sociais aplicada., Campos dos Goytacazes, 19 (7), 54-64, 2017

seer.perspectivasonline.com.br 
Rubim (2012) percebe a arte como linguagem humana, que segue o termo das mudanças históricas e também da forma de viver das pessoas. Caso mantenha-se a perspectiva da Arte como sendo constitutiva do fazer do homem, na sua totalidade, dever-se-á valorizar o sentido ético, o sentido cognitivo e o sentido da sensibilidade do mesmo. Nesse processo, percebe-se que a música, bem como outras formas de linguagem,

\begin{abstract}
“(...) permite gerar uma nova sensibilidade, disseminar novos valores, ideias e comportamentos indispensáveis para o desenvolvimento e a conservação da sociedade, tornando-se um instrumento de educação dos homens. Dessa forma, atribuímos à sensibilidade um papel de destaque ao processo de formação humana (...) Torna-se crucial, desse modo, desenvolver a sensibilidade humana, ampliando, assim, a dimensão da reflexão.“(RUBIM, 2012, pág.04)
\end{abstract}

$\mathrm{Na}$ avaliação de Souza et al. (2010), é bastante significativa a lista de favorecimentos criados pela Arte na direção do desenvolvimento humano e da reflexão sobre questões sociais. Segundo os autores, a produção artística contribui para ampliação das experiências perceptivas, aguçando e potencializando a capacidade de interpretação e julgamento das pessoas. Isto implica, acreditam tais educadores, o exercício da sensibilidade, o enfoque das emoções do indivíduo e a livre-expressão da subjetividade por meio de diferentes formas de comunicação.

As informações alcançadas, até o momento, sobre a rede de apoio ao sujeito drogadicto e sua família em Campos dos Goytacazes, indicaram os mais variados tipos de Instituições, demandando um entendimento conceitual do que diferenciaria cada uma destas instituições.

Segundo Cardoso (2006) o primeiro grupo de AA da história foi realizado no Hospital Municipal de Akros, em Ohio (EUA), nos meados de 1930. A partir de então os grupos de AA foram crescendo e de acordo com o autor, um dos seus principais critérios era, e ainda hoje é, o seu financiamento exclusivamente interno e o anonimato como um princípio mantido com muito rigor.

Lima e Braga (2012) confirmam a informação que essa organização surgiu nos EUA, em 1935, e se espalhou por todo o mundo. Inicialmente, os grupos tinham a presença massiça de alcoolistas. De acordo com os autores, estes sujeitos compartilhavam suas experiências e dificuldades com a dependência e sustentavam financeiramente a organização por meio de suas contribuições voluntárias.

O Manual de Identidade Visual dos Alcóolicos Anônimos, explicita que a marca deste grupo tem como símbolo um triângulo que representa os três legados de A.A - Recuperação, Unidade e Serviço. O Círculo presente na imagem simboliza o mundo inteiro de A.A, já a cor escolhida para identidade visual, que é o azul, tem o objetivo de sugerir sentimentos como: calma, confiança, leveza, liberdade e harmonia.

De acordo com Lima e Braga (2012), atualmente, o Alcoólicos Anônimos se caracteriza por uma instituição que reúne pessoas em situação de dependência química, e explicam que as reuniões são frequentes e voluntárias, buscando colaborar com a prática de abstinência.

Lima e Braga (2012) ressaltam ainda que não há resultados definitivos sobre a eficiência de AA, mas acredita- se que esta instituição, que acolhe milhares de pessoas que precisam de apoio no mundo inteiro, e tem sido caracterizada como de grande importância para o bem-estar, a diversidade no cuidado e o tratamento continuado dos sujeitos dependentes.

Estudar as experiências dos alcoolistas, através de como elas são vivenciadas pelos próprios participantes, ou seja, por aqueles que se reconhecem como "doentes alcoólicos", é um dos objetivos do AA segundo Campos(2005), sendo possível perceber ao longo dos encontros os significados e representações da expressão "doença alcoólica". Para os autores, quando os membros do AA estão em grupo assumem o modo de construção e de identidade redentora que grupo intenciona.

Os estudos de Campos (2009) revelaram que a irmandade de A.A vem se destacando e despertando a atenção pelo seu grande crescimento em escala mundial, com destaque, no Brasil. Nestes estudos o autor define o AA como um agrupamento que reúne sujeitos de diferentes idades, classes sociais e sexo, todos em busca da entidade de A.A com uma forma de encontrar apoio para superar a chamada doença do alcoolismo, que os levou a experiência, em muitos casos, de exclusão e marginalidade social.

$\mathrm{O}$ autor destaca também que, apesar dos encontros acontecerem coletivamente, a forma de tratamento de A.A é direcionada para a recuperação individual de cada sujeito, e considera o alcoolismo

Persp. online: hum. \& sociais aplicada., Campos dos Goytacazes, 19 (7), 54-64, 2017

seer.perspectivasonline.com.br 
como uma doença incurável e progressiva, de base física e espiritual. O anonimato é, desta forma, caracterizado como um mecanismo simbólico de grande importância no processo de recuperação dos membros do A.A, implicando o auto-reconhecimento do sujeito como "doente alcoólico em estado de recuperação" para que a partir de então ocorra uma reconstruir sua identidade por meio de uma modelo terapêutico no qual pode modular a sua subjetividade.

O Programa de A.A. que tem sido utilizado ao longo das décadas é simples em sua estrutura e já publicado nos mais variados idiomas. O material intitulado "Os doze passos", publicado pela Junta de Serviços Gerais de A.A. do Brasil, descreve cada um dos doze passos a serem seguidos por alguém que ingresse no grupo, e explicita o sistema utilizado:

O Sucesso do programa de A.A. deve-se ao fato de que quem não está bebendo tem uma excepcional facilidade de ajudar um bebedor problema. Esta é a simplicidade do Programa de A.A. Quando um alcoólico recuperado pelos passos, relata seus problemas com a bebida, descreve como está sua sobriedade e o que encontraram em A.A. e abordam um provável ingressante a experimentar essa possibilidade. (JUNAAB, pag.1, 2015/2016)

Este mesmo programa tem sido adaptado com o consentimento do AA, para diversas outras finalidades especificas que implicam a necessidade de controle e sobriedade. É o caso dos Neuróticos Anônimos - N/A.; os Dependentes de Amor e Sexo Anônimos - D.A.S.A.; os Narcóticos Anônimos; os Comedores Compulsivos Anônimos; Consumidores Compulsivos Anônimos, entre outros.

O grupo de AA é frequentado também por pessoas que além da adição ao álcool, apresentam quadros de dependência química de outras substâncias. Isto ocorre porque, em muitos casos, o descontrole da consciência gerado pelo álcool acaba levando a ingestão de outras drogas. Todavia os Narcóticos Anônimos se desenvolveram com o objetivo de ajudar a pessoas com adicções específicas de substâncias químicas que não o álcool.

De acordo com o livreto de introdução à Irmandade de Narcóticos Anônimos, essa entidade tem como finalidade ajudar homens e mulheres que perderam o controle diante do uso de drogas. A irmandade não tem fins lucrativos, a modalidade de tratamento prima pela abstinência das substâncias químicas e para tornar-se participante do grupo é preciso apenas que tenha vontade de parar de usar. A sociedade de NA acompanha princípios teóricos similares ao AA que devem ser seguidos por seus membros de maneira diária. Quando um sujeito está disposto a se libertar desse sofrimento, o NA propõe o inicio de uma trajetória marcada por passos, mais especificamente doze passos a serem seguidos. Este mesmo processo é identificado nos grupos de AA.

Fróis (2007) descreve-nos o padrão mantido pelo NA a ser seguido nos dias de reunião. Ao iniciar as reuniões todos os membros sentam em volta de uma mesa, ou de acordo com o modelo e espaço da sala; o coordenador dá início a um momento de leitura e convida sempre um membro a fazer uma pequena narrativa de suas experiências pessoais com relação a sua história na dependência de substâncias. O autor explica que as reuniões duram em média 90 minutos e os participantes tem o tempo médio de 3 minutos para o seu compartilhar, a fim de que ninguém que deseje deixe de falar sobre suas questões.

Ribeiro-Andrade e Gomes (2016), afirmam que várias são as modalidades de tratamentos para a dependência química: internações compulsórias ou voluntárias, internações hospitalares ou domiciliares, clínicas particulares ou instituições públicas.

Dentre estas, a internação em Comunidades Terapêuticas (CT), constituem-se em parte importante da realidade de apoio ao sujeito drogadicto em Campos. Infere-se que não apenas nesta cidade, mas em outras realidades do país, as CTs atuam como uma possibilidade de baixo custo, e uma alternativa ao serviço público.

As comunidades terapêuticas, aqui entendidas como instituições de atendimento ao dependente químico, não governamentais, em ambiente não hospitalar, com orientação técnica e profissional, onde o principal instrumento terapêutico é a convivência entre os residentes, surgiram no cenário brasileiro, ao longo dos últimos quarenta anos, antes mesmo de existir qualquer política pública de atenção à dependência química no país (COSTA, 2006, p.2).

Persp. online: hum. \& sociais aplicada., Campos dos Goytacazes, 19 (7), 54-64, 2017

seer.perspectivasonline.com.br 
Publicado no ano de 2010, pela Secretaria Nacional de Políticas sobre Drogas, o Glossário de álcool e drogas (Brasília, 2010), define as CTs como um ambiente estruturado, residencial, que acolhe pessoas com transtornos por uso de substâncias psicoativas que consentem em conviver isoladamente para alcançar a reabilitação.

Fossi e Guareschi (2015) esclarecem que desde o ano de 2011 já é possível conveniar uma CT ao Sistema Único de Saúde (SUS) como serviço de atenção da rede pública, mas na maioria das vezes, esclarecem, as CTs são instituições privadas de caráter religioso confessional, nas quais a religião é a principal estratégia de tratamento.

A Federação Brasileira de Comunidades Terapêuticas (FEBRACT) indica o período de 6 a 9 meses como sendo executado tradicionalmente pelas CTs, mas este período pode variar em função de cada caso.

Perrone(2014) explica que o modelo básico de CT é o residencial, todavia existem outras modalidades que trabalham em regime ambulatorial (hospital-dia), regime de internação de curta duração, ou regime de internação de longa duração.

Segundo Fossi e Guareschi (2015), numa CT, o dia é ocupado com diversas atividades que variam entre atividades laborais, terapêuticas e religiosas. Os autores informam ainda que as famílias não ficam impedidas de visitar os residentes, tendo data e horários definidos pelo local.

O Sistema Único de Saúde (SUS) obedece as diretrizes da política setorial de saúde prevendo a implementação de Centros de Atenção Psicossocial Álcool e outras Drogas (CAPSad) em todo território nacional.

O Ministério da Saúde, em documento publicado no ano de 2003 e em vigor até dias atuais, descreve os CAPSad como unidades de atendimento em saúde mental que oferecem a dependentes de álcool e outras drogas, um programa de cuidados intensivos, com apoio de uma equipe multidisciplinar. O manual informa que CAPS foram criados como uma alternativa terapêutica ao tratamento oferecido nos hospitais psiquiátricos.

De acordo com Lima et al. (2015) os usuários dos CAPS têm acesso a atendimento ambulatorial diariamente, onde recebem atendimentos individuais para administração de medicação, realização de psicoterapia e orientação, além de atendimentos em grupo ou oficinas terapêuticas e visitas domiciliares. Os autores destacam que os usuários também podem repousar nos centros, para realizar desintoxicação que não necessite de uma internação, portanto de caráter ambulatorial.

Segundo Brasil (2015), as práticas dos CAPS-AD são realizadas em ambiente de "portas abertas", e estão presentes nos territórios das cidades, dos bairros. Este documento define que ações dos CAPS podem ser destinadas á comunidade de caráter coletivas, podem ser ações em grupos, ações individuais ao paciente, ou ações destinadas às famílias, envolvendo as mais variadas estratégias de trabalho, tais como: acolhimento diurno e/ou noturno, atenção às situações de crise, práticas corporais, práticas expressivas e comunicativas, ações de reabilitação psicossocial, encaminhamentos aos serviços públicos (atenção básica, urgência e emergência, e serviços hospitalares de referência) e ações de redução de danos.

Brasil (2003) estabelece uma ligação direta entre o trabalho dos CAPS e os hospitais do território, podendo ser hospitais gerais, que possuem leitos reservados para pacientes psiquiátricos, e os hospitais psiquiátricos propriamente ditos.

Outro grupo de apoio encontrado na cidade de Campos trata-se de um trabalho realizado pela Igrejas Católicas trata-se de uma iniciativa da Igreja junto aos toxicômacos e outros dependentes.

O Padre João Ceconelo, juntamente com Cecato e Flores (2011), apresentam os grupos de Pastoral da Sobriedade como uma resposta ao problema social e de saúde pública do uso de drogas. Afirmam que a Pastoral vai além da dependência química, e inclui o que convencionou-se chamar de "Terapia do Amor ", que trata todo e qualquer tipo de dependência propondo uma mudança de vida, valorização da pessoa humana reinserção social.

$\underline{\text { Dados sobre a rede de apoio localizada em Campos dos Goytacazes }}$

Persp. online: hum. \& sociais aplicada., Campos dos Goytacazes, 19 (7), 54-64, 2017

seer.perspectivasonline.com.br 
Nesta primeira etapa da pesquisa o trabalho consistiu no levantamento das informações das instituições de apoio ao sujeito drogadicto e seus familiares em Campos dos Goytacazes, tendo o mesmo mostrado-se bastante árduo. Constatou-se que as informações não estão centralizadas em um órgão específico, nem vinculadas em uma única fonte de dados. Destaca-se que as informações identificadas na internet, repetidas vezes mostraram-se desatualizadas o que demandou das pesquisadoras, o exercício de confirmação de cada um dos dados que iam sendo obtidos.

Das instituições de apoio ao sujeito drogadicto, os grupos de Alcóolicos Anônimos apresentaram-se em maior número durante a investigação. Dados como o nome dos grupos existentes na cidade, os dias de reuniões dos grupos e os endereços, estavam dispostos de maneira acessível na internet e por meio destes dados primários foi possível chegar presencialmente no Escritório Central dos Alcóolicos Anônimos em Campos. Nesta visita, a maior parte dos dados sobre os grupos em funcionamento foi confirmada. Todavia, novas informações foram disponibilizadas pelo responsável ao atendimento do público. Verificou-se a existência de grupos de AA cujas informações não foram incluídas no site do órgão. Identificou-se também algumas alterações nas informações dos grupos já existentes, como por exemplo, o dia dos encontros.

A visita ao escritório central de AA revelou uma importante informação que precisa e merece ser vinculada de maneira mais acessível à população: a família de um alcoolista também pode ser assistida por meio de encontros em grupos do Alcóolicos Anônimos. No Escritório Central de AA Campos, o familiar pode ser acolhido individualmente, receber orientação quanto a situação que vive e receber ajuda. Além disso, os familiares podem ser acolhidos também em qualquer grupo de AA da cidade, com a ressalva de que será recebido na mesma reunião que os alcóolicos. Uma vez identificada a presença de um familiar, automaticamente a reunião do dia é declarada "reunião aberta", e o compartilhar passa a envolvê-lo também.

Foram identificados e confirmados 13 grupos de AA distribuídos em diversos bairros da cidade, e além disso, esta primeira etapa de busca levou as pesquisadoras a existência de 7 grupos de Narcóticos Anônimos.

Os Centros de Atenção Psicossocial, conhecidos como CAPS, configuram-se um importante locus de acolhimento para população nas mais variadas necessidades. No que diz respeito à drogadição, o serviço público mantem em Campos o funcionamento do CAPS-AD, ou seja, o Centro de Atenção Psicossocial Álcool e Drogas. Nesta instituição o sujeito pode diariamente ser assistido por profissionais, mas sempre retornando à sua residência. O serviço público local conta também com a existência de dois Hospitais Psiquiátricos, que recebem os encaminhamentos feitos pelo CAPS-AD, quando se faz necessário a internação do paciente. Para os casos de emergência, a população tem como apoio a Emergência Psiquiátrica do posto de Saúde Saldanha Marinho, situado nas imediações do centro da cidade.

Campos dos Goytacazes possui dois Hospitais Psiquiátricos e uma Emergência Psiquiátrica nas imediações do centro da cidade. Um dos Hospitais é administrado pela Liga Espírita de Campos, e recebeu as pesquisadoras de forma positiva para dar as informações. O mesmo não ocorreu no segundo Hospital, que tem apresentado uma resistência em prestar informações que seriam inclusive de domínio público. Quanto a emergência psiquiátrica que recebe o sujeito drogadicto em caso de surtos pelo uso da droga, ou em casos de overdose, uma enfermeira esclareceu o procedimento utilizado neste atendimento. Explicou que, após serem atendidos, os pacientes podem permanecer na unidade de emergência no máximo até 72 horas. Muitos deles chegam por vontade própria pois tem consciência de que estão se sentindo mal, e outros chegam levados por familiares ou pessoas próximas que presenciam o surto. Ao passar às 72 horas o paciente tem alta e só pode sair de lá com algum acompanhamento familiar, caso o paciente não tenha a presença de nenhum parente ele é encaminhado para o CAPS-AD ou para o Centro de Referência Especializado para Pessoas em Situação de Rua - Centro POP.

Sete Comunidades Terapêuticas foram localizadas até o presente momento em Campos, e ao que tudo indica, ainda existem outras comunidades a serem encontradas até o final da pesquisa. Uma problemática identificada implica o fato de que as Comunidades Terapêuticas da cidade, em sua maioria, não dispõe de informações disponíveis na internet. Isto aponta para um prejuízo na acessibilidade ao público, que tem nas mídias sociais e em sites como o Google uma das grandes ferramentas na busca de informações.

As Comunidades encontradas geralmente são organizações de cunho religioso, sendo mantidas financeiramente em parte por igrejas e em parte pelos familiares dos internos quando podem ajudar. Algo

Persp. online: hum. \& sociais aplicada., Campos dos Goytacazes, 19 (7), 54-64, 2017 
que repetiu-se nestas instituições foi a precariedade no que diz respeito a estrutura física e as atividades terapêuticas oferecidas, em função da restrição financeira que todas elas vivenciam. Todas elas funcionam em regime de internato e todas são homogêneas quanto ao gênero, tendo sido possível perceber que a maioria destas são exclusivamente para homens.

Em Campos dos Goytacazes o modelo de atendimento identificado em todas as CTs foi o residencial, não tendo sido localizada, até o momento, nenhuma CT vinculada ao SUS, mantendo assim o caráter de instituições privadas e religiosas.

Também de cunho religioso, a pesquisa apontou para a existência de três grupos que fazem parte da Pastoral da Sobriedade, um trabalho desenvolvido por Igrejas Católicas em Campos. Estes grupos mantém encontros semanais com pessoas que por algum motivo, estão em um processo de retomada de sua sobriedade, como os casos de sujeitos depressivos ou com outros transtornos psicológicos ou psiquiátricos, bem como o caso de sujeitos drogadictos. A pesquisa já conseguiu reunir os dados a respeito de um destes grupos, e alcançou o número de telefone dos dois outros em questão.

\section{CONCLUSÕES}

Ao longo do levantamento chegou-se a informação de que no ano de 2014 um órgão chamado Serviço de Proteção Social para Pessoas com Dependência Química foi criado na cidade de Campos. Todavia, ao buscar contato com o referido órgão, verificou-se que o mesmo havia sido desativado. Alguns informaram que isto teria ocorrido em função de baixa procura por parte da população, outros afirmam que o motivo teria sido de ordem politico-financeira, em função da precariedade na liberação de verbas para manutenção do órgão.

A rede de apoio localizada mostrou-se diversificada quanto a sua tipologia, sendo as instituições religiosas as de maiores expressão.

Acerca dos grupos de AA, NA e Pastoral da Sobriedade, as informações levantadas serão sucedidas por visitas e participação com objetivo de apresentar ao sujeito drogadicto e sua família que ainda não são usuários do serviço, um esclarecimento mais prático sobre as reuniões destes grupos.

A hipótese inicial seria a possibilidade de localizar dados necessários em frentes específicas de acolhimento, mas a realidade encontrada na cidade mostra que a rede de apoio não está conectada, ou seja, não mantém entre si um vínculo de comunicação a favor dos sujeitos que precisam do atendimento.

Desta forma, conclui-se que com os dados já identificados é possível iniciar a editoração do livreto que será distribuído publicamente, todavia, entende-se que o levantamento de informações que inicialmente imaginou-se ser apenas uma primeira etapa, deverá ser mantido até o final do projeto, uma vez que cada nova informação adquirida, poderá representar uma porta de apoio para alguém.

\section{REFERÊNCIAS}

ALVES, V. S. Modelos de atenção à saúde de usuários de álcool e outras drogas: discursos políticos, saberes e práticas. Cad. Saúde Pública, Rio de Janeiro, v. 25, n. 11, 2009.

BRASIL, Ministério da Saúde. A política do Ministério da Saúde para a atenção integral a usuários de álcool e outras drogas. Brasília, 2003.

BRASIL, Ministério da Saúde. Centros de Atenção Psicossocial e Unidades de Acolhimento como lugares da atenção psicossocial nos territórios. Secretaria de Atenção à Saúde. Departamento de Atenção Especializada e Temática, Brasília, 2015.

CAMPOS, Edemilson Antunes de. Porque os alcoólicos são anônimos? Anonimato e identidade no tratamento do alcoolismo. Interface (Botucatu) vol.13 no.28 Botucatu Janeiro-Março. 2009.

Persp. online: hum. \& sociais aplicada., Campos dos Goytacazes, 19 (7), 54-64, 2017

seer.perspectivasonline.com.br 
FRÓIS, Catarina Oliveira. A reinvenção do eu através do discurso: narrativa, estigma e anonimato nas Famílias Anônimas. Mana vol.13 no.1 Rio de Janeiro Apr. 2007

CARDOSO, R. M. M. Só por hoje: Um estudo sobre Narcóticos Anônimos, Estigma Social e Sociedade Contemporânea. Dissertação (Mestrado em História). Instituto de Ciências Humanas e Filosofia, Universidade Federal Fluminense, Niterói, 2006.

LIMA, H. P.; \& BRAGA, V. A. B. Grupo de autoajuda como modalidade de tratamento para pessoas com dependência de álcool. Texto contexto - enferm. vol.21 no.4 Florianópolis Outubro- Dezembro 2012.

CECONEllo, J.; CECATO, S.V.; FLORES,E.B. Pastoral da Sobriedade : consolidando a caminhada. 2. ed. Curitiba, PR : Vitória, Ed. Gráfica \& Editora, 2011.

COSTA, S. F. As políticas públicas e as comunidades Terapêuticas no atendimento à dependência química. Palestra proferida no I Fórum sobre Dependência Química de Maringá, em 28 de junho de 2006.

Federação Brasileira de Comunidades Terapêuticas (FEBRACT). Comunidades Terapêuticas FiliadasTitulares e Provisórias. [página na Internet] [acessado 2012 mar 11].

FOSSI, L.B.; GUARESCHI, N.M.F. O modelo de tratamento das comunidades terapêuticas: práticas confessionais na conformação dos sujeitos. Estud. pesqui. psicol., Rio de Janeiro, v. 15, n. 1, p. 94-115, abr. 2015 .

GIL, A.C. Como elaborar projetos de pesquisa. São Paulo: Atlas, 5. Edição, 2010.

Glossário de álcool e drogas / Tradução e notas: J. M. Bertolote. Brasília: Secretaria Nacional de Políticas sobre Drogas, 2010.

HENRIQUE, I.F.S.; MICHELI, D.; LACERDA, R.B.; LACERDA, L.A.; \& FORMIGONI, M. L.O.S. Validação da Versão Brasileira do Teste de Triagem do Envolvimento com Álcool, Cigarro e Outras Substâncias (ASSIST). Rev. Assoc Méd Bras. São Paulo, 2004.

JUNAAB.Os doze passos. Junta de Serviços Gerais de A.A. do Brasil. Alcoólicos Anônimos do Brasil 2015/2016.

LIMA, M.Z.; RODRIGUES-NETO,E.M.; COELHO, M.O.; MARQUES, L. A. R.V.;\& LOTIF, M.A.L.Percepção do cuidado em saúde no CAPSad: uma visão do paciente. Revista Saúde, Santa Maria, Vol. 41, n. 1, Jan./Jul, p.239-248, 2015.

PERRONE,P.A.K. A comunidade terapêutica para recuperação da dependência do álcool e outras drogas no Brasil: mão ou contramão da reforma psiquiátrica? Ciência \& Saúde Coletiva, 19(2):569-580, 2014.

PINHEIRO, T.F.; RANGEL, I.R.G.; LIMA, R.M.. Estudo da Drogadição Entre Adolescentes de Instituições Públicas do Município de Campos dos Goytacazes (Rj). Anais do XVI Encontro Latino Americano de Iniciação Científica e XII Encontro Latino Americano de Pós-Graduação - Universidade do Vale do Paraíba,2011. 
RIBEIRO-ANDRADE, É.H. Psicanálise e sujeitos em situação de drogadição. Revistas Perspectiva on Line Sociais e Aplicadas. V.3, num. 7, $2013 \mathrm{a}$.

RIBEIRO-ANDRADE, É.H. Livre Arbítrio e Drogadição: A Capacidade Volitiva e o Uso Nocivo de Álcool e Drogas Ilícitas. Dissertação para a obtenção do título de Mestre em Cognição e Linguagem.

Universidade Estadual Norte Fluminense, 2013b.

RIBEIRO- ANDRADE,É.H.;GOMES, G.L. Drogadição e liberdade. Cia do eBook, 2016.

RIBEIRO, F.M.L.; MYNAIO, M.C.S.. As Comunidades Terapêuticas religiosas na recuperação de dependentes de drogas: o caso de Manguinhos, RJ, Brasil. Interface (Botucatu). Rio de Janeiro, 2015.

RUBIM, S.R.F. Sensibilização e Educação de pessoas jovens e adultas por meio da apreciação imagética. IX ANPED-Sul. Seminário de Pesquisa em Educação da Região Sul, 2012.

SANCHEZ, Z.V.D.M; OLIVEIRA, L.G.;RIBEIRO, L.A.; \& NAPPO, S.A. O papel da informação como medida preventiva ao uso de drogas entre jovens em situação de risco. Ciênc. Saúde coletiva, Rio de Janeiro, v. 15, n. 3, p. 699-708, May 2010.

SILVA, C.C.; BENCKE, J. Informação: a chave da prevenção ao uso de drogas. Jornal on line $\mathrm{O}$ Informativo do Vale. 2015. Acesso em 14/06/2016.

SOUSA, F.G.; FERNANDES, F.M.B.; VASCONCELOS, N.S.L.S.; RIBEIRO, L.; \& SANTOS, F.G.V. O teatro como instrumento de sensibilização para educação ambiental. V CONNEPI. Congresso NorteNordeste de Pesquisa e Inovação. Alagoas, 2010. 